Kabir et al., 2009

Stamford Journal of

Pharmaceutical Sciences

S. J. Pharm. Sci. 2(1): 27-31

\section{In Vitro Release Kinetics Study of Different Brands of Esomeprazole Sustained Release Tablets Available in Bangladesh}

Abul Kalam Lutful Kabir ${ }^{1}$, Tasbira Jesmeen ${ }^{1}$, Md. Mesbah Uddin Talukder ${ }^{2}$, Abu Taher Md. Rajib ${ }^{1}$, D.M. Mizanur Rahman ${ }^{1}$

Department of Pharmacy, Stamford University Bangladesh ${ }^{1}$

51 Siddeswari Road, Dhaka-1217

Department of Pharmacy, The University of Asia Pacific ${ }^{2}$,

Dhaka-1209, Bangladesh

\section{Corresponding Author}

Abul Kalam Lutful Kabir

Lecturer, Dept. of Pharmacy

Stamford University Bangladesh

Contact no.: 01552377029

E. mail- Ikabir81@yahoo.com

Received- 5 November, 2008

Accepted for Publication-10 January, 2009

\begin{abstract}
Commercially available four national and four international brands of esomeprazole magnesium sustained release matrix tablets were studied in simulated gastric medium $(\mathrm{pH} 1.2)$ for 2 hours and simulated intestinal medium ( $\mathrm{pH} \mathrm{6.8)} \mathrm{for} 8$ hours time period using USP reference dissolution apparatus. All the national and international brands complied with the USP in-vitro dissolution specifications for drug release in simulated gastric medium. However, one of the national brands (Code: MP-1) and one of the international brands (MP7) failed to fulfill the official requirement of $80 \%$ drug release within $8^{\text {th }}$ hour in simulated intestinal medium. Drug release of that national and international brand were $70.49 \%$ and $67.05 \%$ respectively within the specified time period, however one national brand (Code: MP-4) released $103.46 \%$ drug within $8^{\text {th }}$ hour in intestinal medium. Drug release profiles were analyzed for zero order, first order and Higuchi equation to reveal the release kinetics perspective of esomeprazole magnesium sustained release matrix tablets. It was found that zero order release kinetics was the predominant release mechanism than first order and Higuchi release kinetics for those brands (Code: MP-2, MP-3, MP-4, MP-5, MP-6 and MP-8) which complied with the USP in vitro dissolution specification for drug releases. On the other hand, first order release kinetics was predominant for one national and also one international non compliant brands (Code: MP-1 and MP-6).
\end{abstract}

Key Words: In vitro dissolution, Sustained release, Market preparations, Kinetic analysis, Esomeprazole, National brand, International brand.

\title{
INTRODUCTION
}

Esomeprazole, the S-isomer of omeprazole, irreversibly inhibits the gastric parietal $\mathrm{H}^{+} / \mathrm{K}$-ATPase enzyme involved in the production of hydrochloric acid in the stomach. It acts as proton pump inhibitor, used to treat gastroesophageal reflux disease (GERD), erosive esophagitis, and gastric ulcer etc. (Martindale, 2005). The process of in vitro dissolution played a vital role in liberating the drug from the tablet matrix and marking whether it is available for subsequent gastrointestinal absorption. The in vitro dissolution of the drug from the tablet matrix depends on many factors, which include not only the physiochemical properties of drug, but also the nature of formulation and the process of manufacturing (Augsburger et al, 1983). Hence in vitro dissolution analysis of pharmaceutical dosage form has emerged a very important parameter that ensured product quality as well as for differentiating among formulations of the same therapeutic agent (Ayres et al., 1984). For sustained release tablets the role of in vitro dissolution becomes still more crucial as an additional coating step involved in the manufacturing process (Lordi, 1992). In vitro dissolution study is an important tool in the evaluation of the best formulation and also in the understanding of possible risks related to specific gastrointestinal environment, dose dumping, food effects on bioavailability and interaction with other drugs (Sungthongjeen et al., 1999). Today dissolution studies are the most frequently used tools in the development, characterization and utilization processes of controlled release formulations (Longer et al., 1990).

In Bangladesh there are a number of pharmaceutical companies manufacturing and marketing sustained release matrix tablet of esomeprazole. Besides the national brands, there are few international brands also available in drug stores. This study deals with the comparative in vitro dissolution or in vitro bioavailability characteristics of sustained release matrix tablets of most commonly available national and international brands of esomeprazole in Bangladesh. 


\section{MATERIALS AND METHODS}

Drug: Esomeprazole magnesium (Square Pharmaceuticals, Bangladesh); Solvents and reagents: Hydrochloric acid (Merck, Germany); ortho-phosphoric acid (Merck, Germany); Potassium di hydrogen phosphate (Merck, Germany); Sodium Hydroxide (Merck, Germany); Equipments: Single Punch Tablet press (Shanghai-Tianhe Pharmaceutical Machinery Company); UV Spectrophometer (Shimadzu, Japan); Digital pH meter (Hach Company, USA); Electronic Hardness tester (Ereweka, Germany); Tablet Dissolution Tester (Electrolab, India); Sartorius Electronic Balance.

\section{Dosages forms}

Four national and four international brands of marketed (production date not more than four months ago from the time of purchase) esomeprazole sustained release matrix tablets of the test drug were collected from various stores. The samples were properly checked for their manufacturing license number, batch number, and date of manufacture and expiry dates before purchasing. These were randomly coded (MP-1, MP-2, MP-3 and MP-4) for national brands and (MP-5, MP-6, MP-7 and MP-8) for international brands. The labeled active ingredient was esomeprazole $20 \mathrm{mg}$ and packaged in strip or in blister packing. The strip or blister packs stored at $25 \pm 2^{\circ} \mathrm{C}$ for four weeks before the dissolution study in order to evaluate any change in organoleptic properties.

Table 1: Multiple coefficients $\left(R^{2)}\right.$ and diffusion exponent $(n)$ values of different brands of national and international esomeprazole magnesium sustained release tablets available in Bangladesh Pharma market

\begin{tabular}{ccccc}
\hline Code & \multicolumn{2}{c}{ Multiple coefficient of determination $\left.\mathbf{R}^{2}\right)$} & \multirow{2}{*}{$\begin{array}{c}\text { Diffusion } \\
\text { exponent(n) }\end{array}$} \\
\cline { 2 - 4 } & Zero order & First order & Higuchi & \\
\hline MP-1 & 0.95 & 0.91 & 0.89 & 1.05 \\
\hline MP-2 & 0.99 & 0.92 & 0.90 & 1.10 \\
\hline MP-3 & 0.99 & 0.93 & 0.87 & 1.20 \\
\hline MP-4 & 0.99 & 0.90 & 0.85 & 1.0 \\
\hline MP-5 & 0.98 & 0.91 & 0.88 & 1.11 \\
\hline MP-6 & 0.98 & 0.93 & 0.87 & 1.05 \\
\hline MP-7 & 0.98 & 0.95 & 0.90 & 0.99 \\
\hline MP-8 & 0.92 & 0.94 & 0.92 & 0.89 \\
\hline
\end{tabular}

\section{In vitro dissolution study}

These studies were conducted at $37 \pm 0.5^{\circ} \mathrm{C}$ on an USP specification dissolution rate test type II apparatus (Paddle apparatus) with six section assembly according to the USP XXIII procedure with minor modification (USP XXII and NF XVII, 1995). For in vitro dissolution studies, simulated gastric medium ( $\mathrm{pH}$ 1.2) and simulated intestinal medium ( $\mathrm{pH}$ 6.8) were used as dissolution media.

\section{a) Preparation of simulated gastric medium $(0.1 \mathrm{~N} \mathrm{HCl} \mathrm{pH} \mathrm{1.2)}$}

For $0.1 \mathrm{~N} \mathrm{HCl}, 11.4 \mathrm{ml}$ of hydrochloric acid $(32 \% \mathrm{w} / \mathrm{v})$ was diluted with sufficient water to produce $1000 \mathrm{ml}$.

\section{b) Preparation of simulated intestinal medium (Buffer $\mathrm{pH}$ 6.8)}

$20 \mathrm{ml}$ sodium hydroxide (25\%) was diluted with $0.1 \mathrm{~N}$ Hydrochloric acid to $1000 \mathrm{ml}$ adjusting $\mathrm{pH}$ 6.8 by the addition of $1.2 \mathrm{ml} O$-phosphoric acid. The dissolution test was performed using $900 \mathrm{ml}$ medium at $37 \pm 0.5^{\circ} \mathrm{C}$ and $100 \mathrm{rpm}$.

The medium was preheated to $37^{\circ} \mathrm{C}$ and then added to the vessels. After that paddle rotation was started and the system was allowed to equilibrate for $15 \mathrm{~min}$. Each vessel, vessel position, and corresponding tablet result were assigned the same number. Thus, for each sub sample of six 
tablets tested simultaneously, every individual tablet result was identified with a particular vessel and position. The total duration of dissolution was 12 hours in which the first 2 hours the tablet matrices were subjected to simulated gastric media $(0.1 \mathrm{~N} \mathrm{HCl} \mathrm{pH} \mathrm{1.3)} \mathrm{and} \mathrm{the} \mathrm{later} 10$ hours the tablet matrices were subjected to simulated intestinal media.

\section{Acid stage}

$900 \mathrm{ml}$ of $0.1 \mathrm{~N} \mathrm{HCl}$ was placed in each vessel and the apparatus was assembled. Six tablets from each formulation were weighed and placed in the baskets. The operation in the acid stage was carried out for 2 hours. After each hour, $10 \mathrm{ml}$ of sample solution was withdrawn and filtered. The released drug was assayed by using UV spectrophotometer at $305 \mathrm{~nm}$.

\section{Buffer stage}

After 2 hours operation in the acid stage, $20 \mathrm{ml} \mathrm{NaOH}(25 \%)$ was added to the previous fluid. The $\mathrm{pH}(6.8 \pm 0.05)$ was adjusted with addition of $1.2 \mathrm{ml} O$-phosphoric acid. The operation was continued for 10 hours. At every one-hour interval, sample $(10 \mathrm{ml})$ of the solution was withdrawn from the dissolution medium and immediately replaced with equal volumes of fresh dissolution medium. The withdrawn samples $(10 \mathrm{ml})$ was then filtered and diluted, analyzed at $305 \mathrm{~nm}$ for esomeprazole by UV spectrophotometer. The amounts of drug present in the samples were calculated from calibration curves constructed from the standard solution of USP reference standard test drug.

\section{RESULTS AND DISCUSSION}

Commercially available four national brands (Code: MP-1, MP-2, MP-3 and MP-4) and four international brands (Code: MP-5, MP-6, MP-7 and MP-8) of esomeprazole sustained release tablets were studied for their in vitro dissolution behavior in simulated gastric medium $(\mathrm{pH} 1.2)$ for 2 hours time period and in simulated intestinal medium $(\mathrm{pH} \mathrm{6.8)}$ for 8 hours time period using USP reference dissolution apparatus to observe the release kinetics of the matrix tablets (Table 1 and Fig. 1-4).

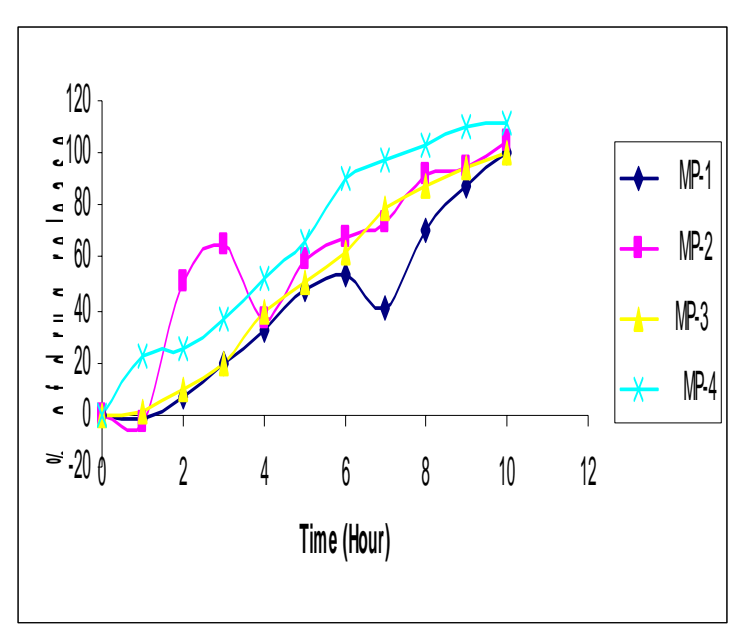

Figure 1a: Zero order plot of release kinetics of four national brands.

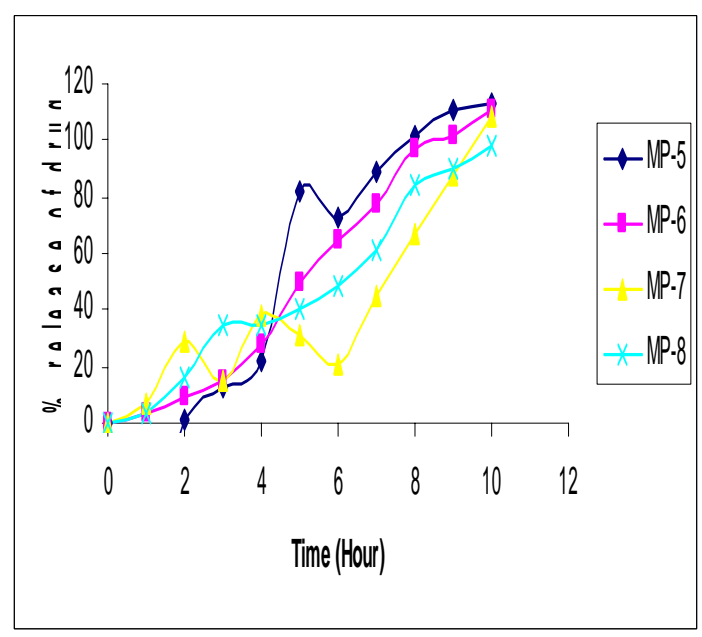

Figure 1b: Zero order plot of release kinetics of four international brands.

All the national and international brands complied with the USP in vitro dissolution specification, i.e., $25 \%$ drug release within 2 hours in simulated gastric medium. After a comprehensive in vitro dissolution study, it denoted that the three national brands (Code: MP-2, MP-3 and MP-4) and three international brands (Code: MP-5, MP-6 and MP-8) fulfilled the USP In vitro dissolution specification ( $80 \%$ drug release within $8^{\text {th }}$ hours) in simulated intestinal medium. Due to formulation defects, one of the national brands (Code: MP-1) and one of the international brands (MP-7) were failed to fulfill the USP in vitro dissolution specification i.e., $80 \%$ drug release within $8^{\text {th }}$ hours in simulated intestinal medium and one national brand (Code: MP-4) released $103.46 \%$ drug within $8^{\text {th }}$ hours in the simulated intestinal medium. The amount of drug present in each tablet was determined by spectroscopic method and except two; all the brands met the official standard. 
Kabir et al., 2009

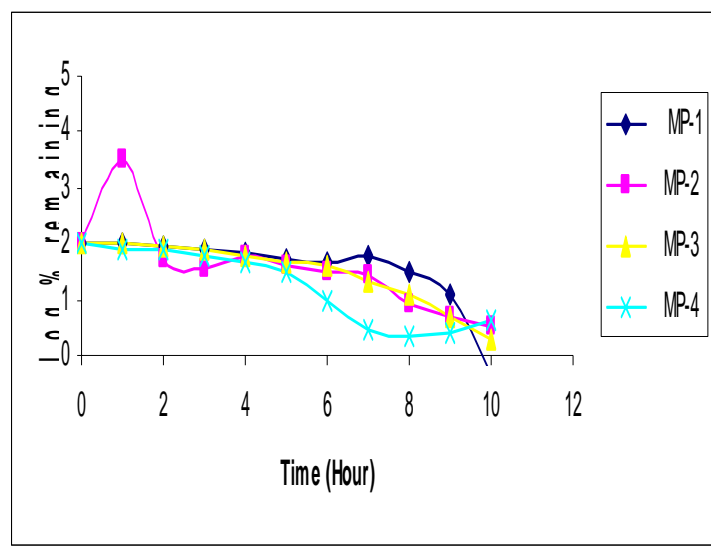

Figure 2a: First order plot of release kinetics of four national brands.

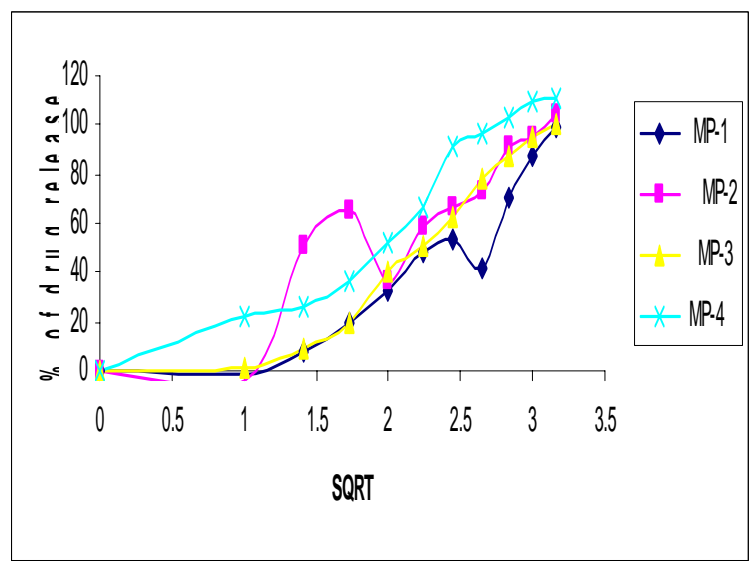

Figure 3a: Higuchi plot of release kinetics of four national brands.

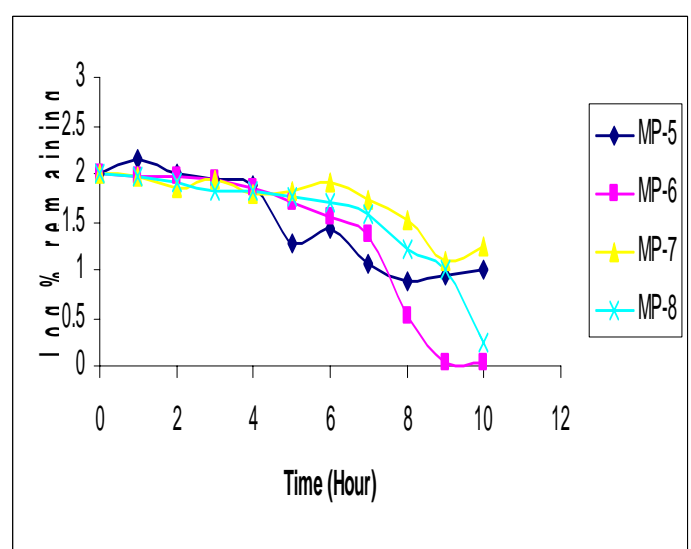

Figure 2b: First order plot of release kinetics of four international brands

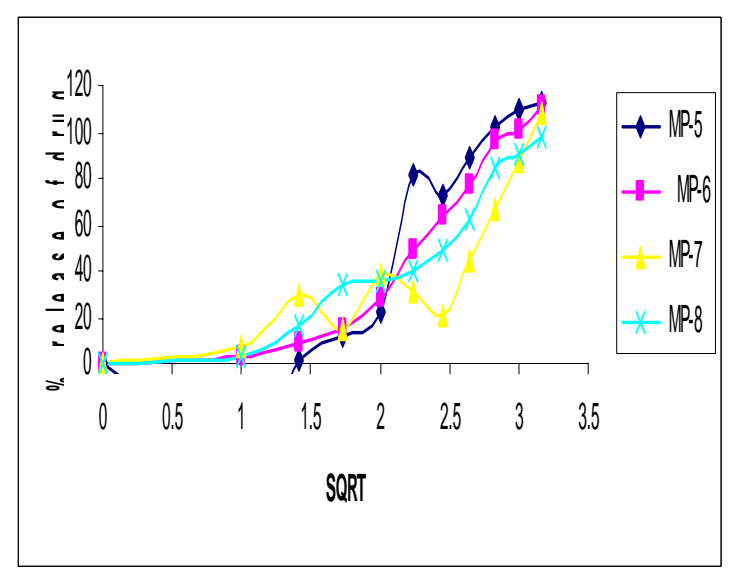

Figure 3b: Higuchi plot of release kinetics of four international brands.

The drug release mechanism was determined by multiple coefficients $\left(r^{2}\right)$ and diffusion exponent (n) for each individual brands (Table 1). A zero order release kinetics was predominant than the first order and Higuchi release kinetics for the national three brands (Code: MP-1, MP-2 and MP-4) and three international brands (Code: MP-5, MP-6 and MP-8). It was focused that the drug release of those brands followed diffusion method and concentration independence from the matrix of tablet. First order release was predominant than the zero order and Higuchi release kinetics for one national and one international non compliant brands (Code: MP-1 and MP-7).

\section{CONCLUSION}

This study revealed that most of the commercially available brands of esomeprazole magnesium sustained release tablets in Bangladesh met the official specification and few of them failed which might have some formulation problems. The study also emphasized the need of constant surveillance on marketed drug product by the government, manufacturers and independent research groups to ensure supply and availability of quality medicines for the patients in Bangladesh. 
Kabir et al., 2009

\section{REFERENCES}

Augsburger LL, Shangraw RF, Giannini RP, Shah VP, Prasad VK and Brown D (1983). Thiazides VIII: Dissolution Survey of marketed Hydrochlorothiazide tablets. J. Pharm. Sci., 72(8): 876-881.

Aulton ME (1988). Pharmaceutics: The Science of Dosage Form Design, 1st edition, LBS/Churchill Livingstone, Edinburgh, p.171.

Ayres JW, Huang $\mathrm{H}$ and Albert $\mathrm{K}$ (1984). Effect of polymer in sustained release matrix tablet. J. Pharm. Sci., 73: 1629.

Goodman and Gilman's (2001). The Pharmacological Basis of Therapeutics. 10th edition. McGraw-Hill Medical Publishing Division, pp.644-646

Haider SS and Ahsan GM (2001). Dissolution profiles of commercially available enteric coated tablets of non steroidal anti inflammatory drugs. J. Bangladesh Acad. Sci., 25(2): 149-155.

Longer MA and Robinson JR (1990). Sustained Release Drug Delivery System, Martindale, 32nd Edition, the 'Complete Drug Reference'2002.p.1225

Remington's Pharmaceutical Science, Chapter 91, 18th edition, pp.1676-1690.

Lordi NG (1992). Sustained Release Dosage Forms. In: Lachman L, Lieberman HA and Kanig JL (Eds.). The Theory and Practice of Industrial Pharmacy, 3rd edition, Varghese Publishing House, Bombay, pp.430-456.

Sungthongjeen S, Pitaksuteepong T, Somsiri A and Sriamornsak P (1999). Studies on pectins as potential hydrogel matrices for controlled-release drug delivery. Drug. Dev. Ind. Pharm., 25(12): 1271-1276.

United States Pharmacopeia XXIII \& National Formulary XVII (1995). United States Pharmacopeia Convention, Inc., Rand McNally, Taunton, p.1950. 